\title{
Foliar injury, growth, and SOD activity of Pinus densiflora exposed to ozone
}

\author{
J.-C. Lee, C.-Y. Oh \& S.-H. Han \\ Department of Forest Genetic Resources, \\ Korea Forest Research Institute, Korea
}

\begin{abstract}
This study was conducted to compare ozone sensitivity among half-sib families of Japanese red pine (Pinus densiflora S. et. Z). Ninety families were exposed in walk-in type chambers to charcoal-filtered air and 100ppb ozone for eight hours daily over a period of five consecutive months. We surveyed the foliar injury, relative diameter at root collar (DRC) growth, and relative dry weight after fumigation. We selected five tolerant families and five sensitive families. After one year, the selected ten families were exposed to 100ppb ozone for 90 days. Every 30 days after ozone fumigation, the DRC, superoxide dismutase (SOD) activity, and malondialdehyde (MDA) content were measured. In the earlier stage of ozone fumigation, the tolerant group showed a relative DRC growth rate three times higher than that of the sensitive group. As well, during the entire fumigation period, the growth rate of the tolerant group was superior to that of the sensitive group. Relative SOD activity in the sensitive group was increased 30 days after fumigation, and in accordance with the fumigation period extended it was decreased. MDA content in the ozone treatment manifested at higher levels than in the control group, and the MDA content of the tolerant group manifested at higher levels than that found in the sensitive group. The tolerant group has more antioxidative activity than the sensitive group; therefore the tolerant group can restrain lipid peroxidation and other adverse effects on physiological activity. Ozone-induced growth reduction may thus be decreased in the tolerant group.
\end{abstract}

Keywords: ozone, open-pollinated family, SOD, MDA, relative growth rate. 


\section{Introduction}

Ozone-induced stomatal closure and mesophyll cell damage, reduction of photosynthetic activity and interruption of physio-biochemicals may lead to a reduction in plant growth (Pye [17], Pääkkönen et al. [16]). We can therefore compare ozone sensitivity between species using visible injury, growth change induced by ozone, and antioxidant activity (Heath [9], Sheng et al. [18], Bergmann et al. [3], Bungener et al. [5]). Recently there have been many studies conducted to determine plant response to ozone, but the physio-biochemical response to ozone may be expressed in complicated ways, and thus it may difficult to determine the exact relationship between ozone and plant growth. So we should consider how damage and tolerant response to ozone to evaluate ozone sensitivity (Bortier et al. [4]).

Currently in Korea, the frequency of ozone warnings and the number of days on which they are issued are increasing; moreover, the highest-concentrationper-hour levels increase every year, so plant damage is expected to be observable in the near future. Intensive studies of ozone-induced harm may be conducted using readily-available native plants. In Korea, various domestic trees and economical plant belonging to Betula spp. and Pinus spp. were studied to find out their damage thresholds and tolerance response. Pinus densiflora, which has one of the largest distribution ranges, is valued for its protective effects and its abundance.

Recently, genetically-modified poplars were used for ozone-tolerance research. This study was conducted on select ozone tolerant families of $P$. densiflora. First, a sensitive group and a tolerant group were selected, using signs of visible injury and growth; second, the ozone sensitivity of each selected family was evaluated; and finally, damage and tolerance response to ozone were determined.

\section{Materials and methods}

\subsection{Pre-selection}

\subsubsection{Plant and ozone treatment}

One-year-old seedlings were collected from 90 families selected from across Korea, and were composed in the Anmyondo seed orchard, Forest Seed Research Center, Korea Forest Research Institute (approximately $36^{\circ} 27^{\prime} \mathrm{N}, 126^{\circ} 22^{\prime} \mathrm{E}$ and 25 50m altitude) (Figure 1). For the ozone treatment, the seedlings were divided into a control (non-ozone) group and a group receiving a 100ppb treatment. Ozone fumigation took place over a period of eight hr/day (from 9 a.m. to 5 p.m.) for five months, in the ozone-treatment facility of the department of Forest Genetic Resources, Korea Forest Research Institute (Lee et al. [15]).

\subsubsection{Damage survey}

After five months of ozone fumigation, representative foliar injury in coniferous tree chlorotic mottle was investigated at six levels $(0=$ none, $1=1 \sim 6 \%, 2=7 \sim 25 \%$, 
$3=26 \sim 50 \%, 4=51 \sim 75 \%, 5=76 \sim 100 \%$ ) (Duriscoe et al. [6]). As well, the diameter at root collar and the dry weight of leaf, stem and root were measured.

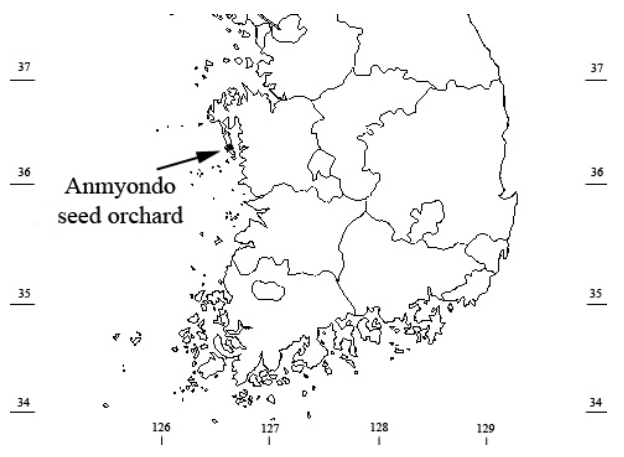

Figure 1: Geographical location of Anmyondo seed orchard of Forest Seed Research Center, Korea Forest Research Institute.

\subsection{Comparison between tolerant and sensitive group}

\subsubsection{Plant and ozone treatment}

Kangwon (KW) 4, 9, 16, 73, and Gyungbuk (GB) 38 were selected for the tolerant group; KW 10, 17, Chungbuk (CB) 1, and GB 3 and 18 were selected for the sensitive group. Ozone treatment was performed on 10 individuals from each family. Ozone treatment was divided between the control (non-ozone) groups and the group receiving $100 \mathrm{ppb}$ treatment. Ozone fumigation was conducted over a period of eight hr/day (from 9 a.m. to 5 p.m.) for three months, in the same ozone chamber as cited above.

\subsubsection{Evaluation of ozone sensitivity}

The diameter at root collar (DRC) was measured every month, and the relative growth rate was calculated using the formula $\left[\operatorname{Ln}\left(X_{2}\right)-\operatorname{Ln}\left(X_{1}\right)\right] /\left(t_{2}-t_{1}\right) \cdot X_{2}$ and $X_{1}$ mean DRC of end time $\left(t_{2}\right)$ and DRC of initial time $\left(t_{1}\right)$ respectively. Superoxide dismutase (SOD) activity in the leaves was measured by nitro blue tetrazolium reducing methods, and activity was determined by absorbance increase over a period of $120 \mathrm{sec}$, with 530nm UV-spec (Beauchamp and Fridovich [1]). Malondialdehyde (MDA) content in the leaves was measured by the method used by Esterbauer and Cheeseman [7], with a slight modification.

\section{Result}

\subsection{Pre-selection}

\subsubsection{Foliar injury}

Every individual in the treatment chamber showed visible injury. The damage level varied significantly among the 90 families. CB 2 was the lowest at $0.9 \%$, while KW 46 was the highest at $28.3 \%$. The 90 families were divided into three 
groups (tolerant, mid-tolerant, and sensitive) of 20 families each there was significant difference between the groups (Figure 2). The injury level of the tolerant group was the lowest at $1.9 \%$, while the level of the mid-tolerant group was $5.3 \%$. In the sensitive group, KW 46, 29, 72, 86, and 23 showed relatively more sensitivity, and the total injury level of the sensitive group was $15.2 \%$. There was thus a large difference in visible injury among families of the same species.

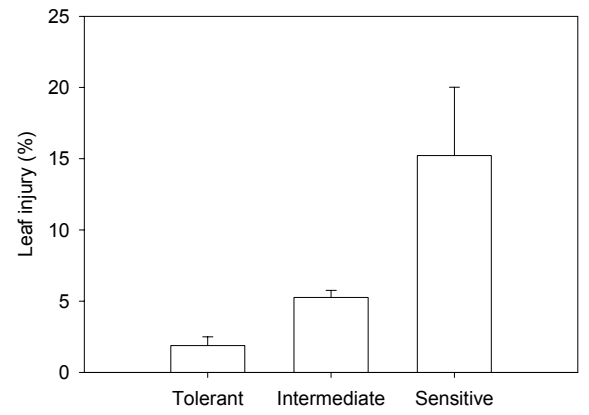

Figure 2: Comparison of the leaf injury among tolerance, intermediate and sensitive groups of $P$. densiflora exposed to $100 \mathrm{ppb}$ ozone for five months. Each data point represents mean \pm standard deviation of at least 3 replicates.

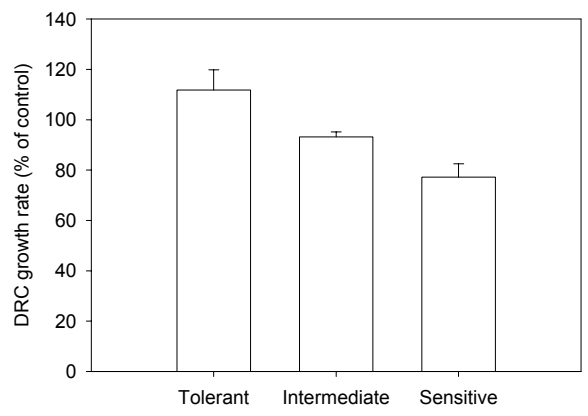

Figure 3: Relative DRC growth rate among tolerance, intermediate and sensitive groups of $P$. densiflora exposed to $100 \mathrm{ppb}$ ozone for five months. Each data point represents mean \pm standard deviation of at least 3 replicates.

\subsubsection{Growth}

The DRC of 64 out of 90 families was more reduced than that of the control group. We divided the total into three groups (tolerant, mid-tolerant, and sensitive) of 20 families each. Each group showed significant difference in growth (Figure 3 ). The DRC of the tolerant group increased by $12 \%$ compared to the control group, but the DRC of the sensitive group decreased by $23 \%$. 
The dry weight of leaf, stem, and root of the tolerant group increased by $23 \%$ for leaf, $38 \%$ for stem, and $8 \%$ for root. Otherwise, the dry weight of the sensitive group decreased by $30 \%$ for leaf and $42 \%$ for root (Figure 4 ).
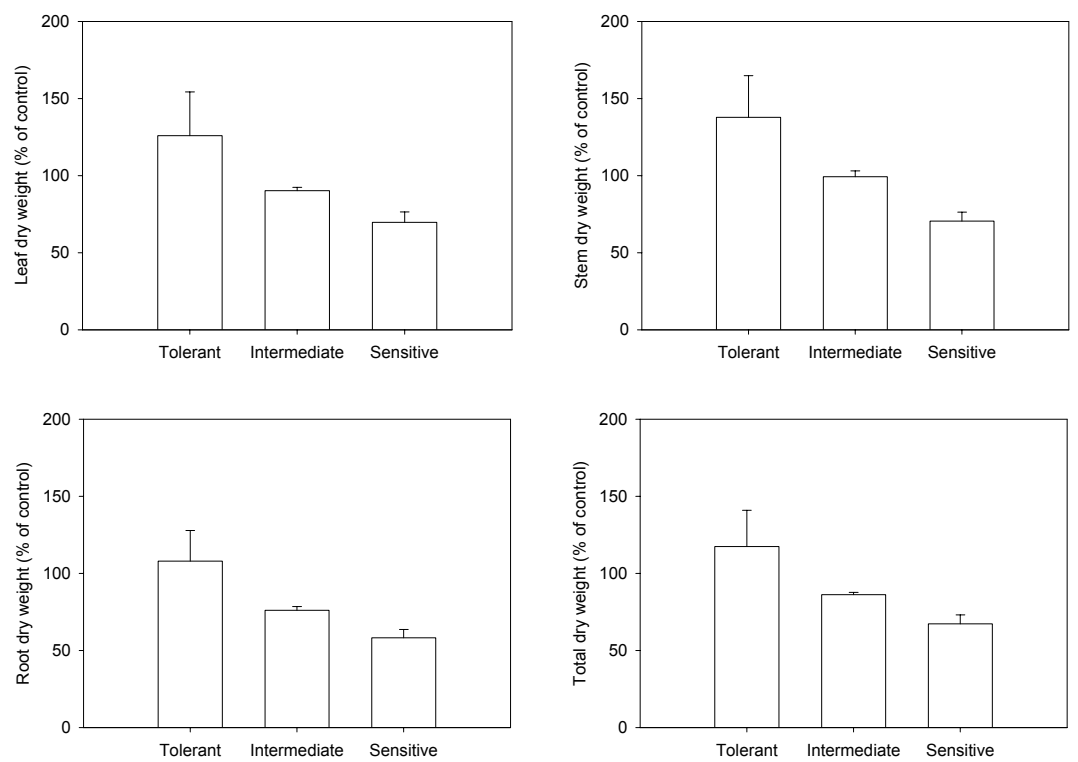

Figure 4: Relative dry weight of leaf, stem, root, and total among tolerance, intermediate and sensitive groups of $P$. densiflora exposed to $100 \mathrm{ppb}$ ozone for five months. Each data point represents mean \pm standard deviation of at least 3 replicates.

\subsection{Comparison between tolerant and sensitive group}

\subsubsection{Growth}

The tolerant group showed a higher level of DRC growth than did the sensitive group over the entire ozone fumigation period (Figure 5). After one month of ozone fumigation, the initial relative growth rate of the tolerant group was 0.063 , but the relative growth rate of the sensitive group was 0.021 . After three months of ozone fumigation, the relative growth rate of the tolerant group was 1.6 times higher than that of the sensitive group. In the tolerant group, KW 9 showed the highest tolerance in the initial state growth rate of ozone fumigation, and KW 10 showed the lowest growth rate. The sensitive group showed different DRC growth patterns in each family during the period of ozone fumigation. KW 10 showed an incremental increase in the growth rate as the fumigation period unfolded, but the growth rate of KW 17 and GB 3 decreased after two months of ozone fumigation. 
(A) Control, tolerant group

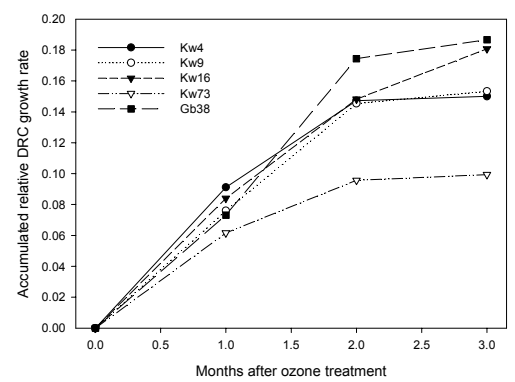

(C) Ozone treatment, tolerant group

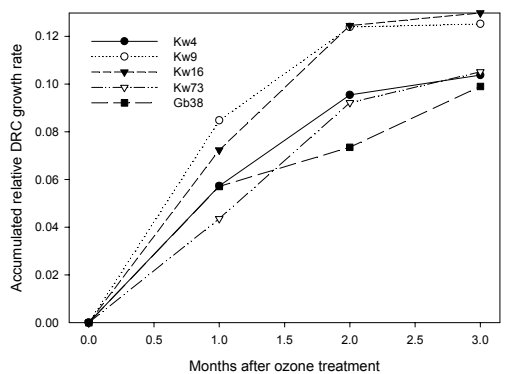

(B) Control, sensitive group

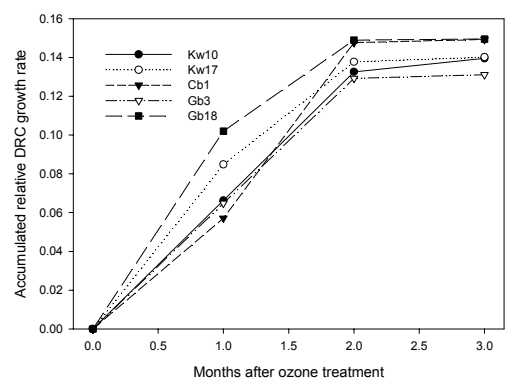

(D) Ozone treatment, sensitive group

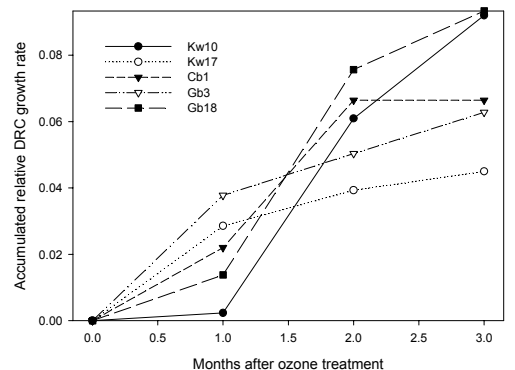

Figure 5: Accumulated relative DRC of $P$. densiflora exposed to $100 \mathrm{ppb}$ ozone for three months. Each data point represents mean of five replicates.
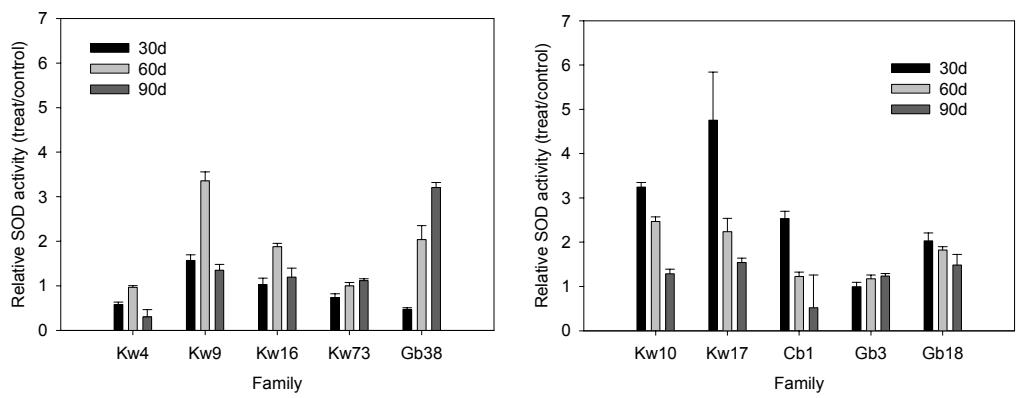

Figure 6: Relative SOD activity of tolerant group (left) and sensitive group (right) of $P$. densiflora exposed to $100 \mathrm{ppb}$ ozone for three months. Each data point represents mean \pm standard deviation of five replicates.

\subsubsection{SOD activity}

The relative rate of SOD activity of treatment to control for the tolerant group was superior to that of the sensitive group (Figure 6). The change in the relative 
rate of SOD activity was different between the tolerant group and the sensitive group; the SOD activity rate of the sensitive group in the initial stage of ozone fumigation was relatively higher than that of the tolerant group, and decreased as the ozone fumigation time increased. Otherwise, the SOD activity rate of the tolerant group increased for two months and then decreased; it also increased continuously in GB 38 during the ozone fumigation period.

\subsubsection{MDA content}

The MDA content rate of the initial stage of the tolerant group and the sensitive group were similar, but as the ozone fumigation increased, the MDA content of the sensitive group increased relatively (Figure 7). KW 10 and GB 18 in the sensitive group increased by $50 \%$ after two months of ozone fumigation compared to the levels after one month. The tolerant group, however, showed little change. GB 3 and GB 18, which were considered tolerant, group were weak in terms of SOD activity; after three months of ozone fumigation, the MDA content rate increased by about $40 \%$ and $60 \%$ for GB 3 and GB 18 respectively.
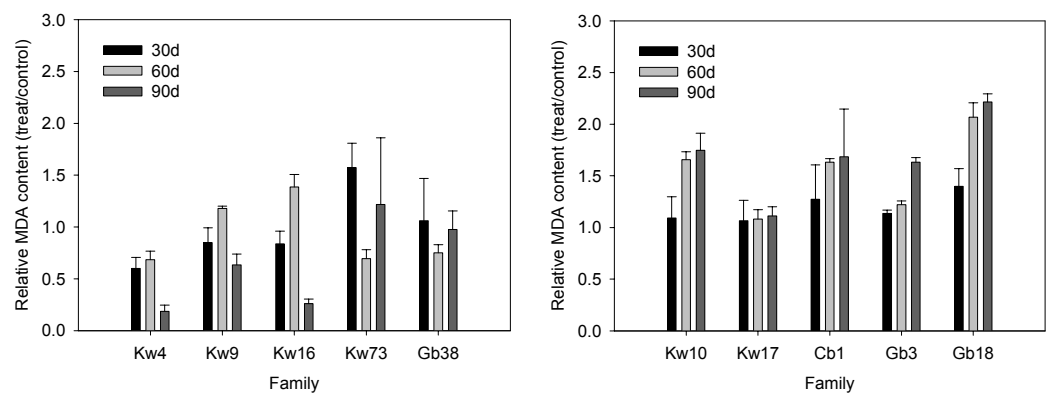

Figure 7: Relative MDA content of tolerant group (left) and sensitive group (right) of $P$. densiflora exposed to $100 \mathrm{ppb}$ ozone for three months. Each data point represents mean \pm standard deviation of five replicates.

\section{Discussion}

Visible injury induced by pollutants was used to determine not only pollutant concentration but also the tolerant response to the interaction of various factors. Weir [20] also reported that visible injury differences in Pinus taeda leaves caused by ozone in a controlled environment were caused by genetic variation. The ideal way to select tolerant individuals for one of the pollutants is in-situ selection. This is difficult to do in a natural setting, however, because genetic characters, environmental factors, or a combination of these complicate the task. Recently, genetic character was clarified as the most important factor among the expressed variations in a controlled environment (Taylor [19]). The results of our study for pre-selection showed different damage responses. As well, the tolerant group and the sensitive group which were fumigated again with ozone fumigated 
showed significant differences from each other, so, depending on their respective genetic characters, their ozone-tolerance response was different.

In general, SOD activity is increased under various stress conditions (Sheng et al. [18]), but it is decreased when stresses are extended or excess stresses are introduced (Bennet et al.[2]). As well, the tolerant difference among species against ozone, antioxidant enzyme responded differently, SOD activity responses are expressed differently according to ozone exposing time (Sheng et al. [18], Lee et al. [14]). SOD activity in response to ozone increased in tolerant species but decreased in sensitive species; however, excessive expression of SOD resulted in visible injury. Finally, growth reduction and death are caused by a decrease of the energy required for growth (Sheng et al. [18]).

In our study, the SOD activity of the sensitive group responded sensitively in the initial stage of ozone fumigation, but tolerant ability activity decreased as fumigation time increased. The tolerant group, however, did not respond sensitively in the initial state, and increased rather than decreased as fumigation exposure increased. SOD activity thus responded differently depending on the ozone-tolerance ability (Karnosky et al. [12]). The antioxidative mechanism of the selected tolerant group was less-damaged than that of the sensitive group, so the tolerant group was superior to the sensitive group in ozone-resistance ability.

Singlet oxygen which is one of the active oxygen induced by ozone reacts with unsaturated fatty acid in the membrane, producing hydrogen peroxide and causing lipid peroxidation of the membrane (Knox and Dodge [13], Hippeli and Elstner [10]). As well, active oxygen interrupts the electron transport chain in photosynthesis, causing photosynthesis to be impeded, leading to physiological disturbance (Guidi et al. [8], Jiri et al. [11]).

In our results, the MDA content of the tolerant group and the sensitive group after ozone treatment were higher than that of the control group, allowing us to confirm ozone-induced lipid peroxidation. The sensitive group also showed higher MDA content than the tolerant group because its ozone-tolerance ability was lower. Thus, extended ozone stress caused growth reduction by cell destruction induced by lipid peroxidation and reduced antioxidative ability in the sensitive group.

\section{Conclusion}

In summary, the response of $P$. densiflora to ozone stress is different among different families depending on their genetic characters. Ozone-sensitive families respond more sensitively to ozone stress, so the antioxidant mechanism and lipid peroxidation may be easily disrupted. Conversely, selected tolerant families have more tolerance to ozone in their biochemical and physiological aspects.

\section{References}

[1] Beauchamp, C. \& Fridovich, I., Superoxide dismutase: Improve assays and an assay applicable to acrylamide gels. Analytical Biochemistry, 44, pp 276-287, 1971. 
[2] Bennet, J.H., Lee, E.H. \& Heggestad, H.E., Biochemical aspect of plant. Gaseous Air Pollutants and Plant Metabolism, Koziol, M.J. \& Whatley, F.R. (Eds.), Butterworth England, pp 413-424, 1984.

[3] Bergmann, E., Bender, J. \& Weigel, H.J., Ozone threshold doses and exposure-response relationships for the development of ozone injury symptoms in wild plant species. New Phytologist, 144, pp 423-435, 1999.

[4] Bortier, J., Vandermerien, K., De Temmerman, L. \& Ceulemans, R., Growth, photosynthesis and ozone uptake of young beech (Fagus sylvatica L.) in response to different ozone exposures. Trees, 15, pp 7582, 2001.

[5] Bungener, P. Balls, G.R., Nussbaum, S., Giessman, M., Grub, A. \& Furher, J., Leaf injury characteristics of grassland species exposed to ozone in relation to soil moisture condition and vapour pressure deficit. New Phytologist, 142, pp 271-282, 1999.

[6] Duriscoe, D., Stolte, K. \& Pronos J., Establishment of monitoring plots and evaluation of trees injured by ozone. Evaluating Ozone Air Pollution Effects on Pines in the Western United Stated. Miller, P.R., Stolte, K.W., Duriscoe, D.M. \& Pronos, J. (Eds.), USDA Forest Service Gen. Tech. Rep. PSW-GRT-155; 35-55.

[7] Esterbauer, H. \& Cheeseman, K.H., Determination of aldehydic lipid peroxidation products: malonaldehyde and 4-hydroxynonenal. Methods in Enzymology, 186, pp 407-421, 1990.

[8] Guidi, L., Tonini, M. \& Soldatini, G.F., Effects of high light and ozone fumigation on photosynthesis in Phaseolus vulgaris. Plant Physiology and Biochemistry, 38, pp 717-725, 2000.

[9] Heath, R.L., Initial events in injury to plants by air pollutants. Annual Review of Plant Physiology, 31, pp 395-431, 1980.

[10] Hippeli, S. \& Elstner, E., Mechanisms of oxygen activation during plant stress: biochemical effects of air pollutants. Journal of Plant Physiology, 148, pp 249-257, 1996.

[11] Jiri, S., Gilbert, M., Weingart, I. \& Wilhelm, C., Thermoluminescence as a tool for monitoring ozone-stressed plants. Environmental Pollution, 123, pp 15-20, 2003.

[12] Karnosky, D.F., Podila, G.K., Gagnon, Z., Pechter, P., Akkapeddi, A., Sheng, Y., Riemenschneider, D.E., Coleman, M.D., Dickson, R.E. \& Isebrands, J.G., Genetic control of responses to interacting tropospheric ozone and $\mathrm{CO} 2$ in Populus tremuloides. Chemosphere, 36, pp 807-812, 1998.

[13] Knox, J.P. \& Dodge, A.D., Singlet oxygen and plants. Phytochemistry, 24, pp 889-896, 1985.

[14] Lee, J.C., Oh, C.Y., Han, S.H. \& Kim, P.K., Changes on photosynthesis and SOD activity in Platanus orientalis and Liriodendron tulipifera according to ozone exposing period. Korean Journal of Agricultural and Forest Meteorology, 7, pp 156-163, 2005. 
[15] Lee, J.C., Kim, I.S., Yeo, J.K. \& Koo, Y.B., Comparing of clonal sensitivity of Populus deltoides to atmospheric ozone with use of visible foliar injury. Journal of Korean Forest Society, 90, pp 10-18, 2001.

[16] Pääkkönen, E., Vahala, J., Holopainen, T., Karjalainen, R. \& Kärenlampi, L., Growth responses and related biochemical and ultrastructural changes of the photosynthetic apparatus in birch (Betula pendula) saplings exposed to low concentrations of ozone. Tree Physiology, 16, pp 597-605, 1996.

[17] Pye, J.M., Impact of ozone on the growth and yield of trees: a review. Journal of Environmental Quality, 17, pp 347-360, 1988.

[18] Sheng, Y., Podila, G.K. \& Karnosky, D.F., Differences in O3-induced Superoxide dismutase and glutathione antioxidant expression in $\mathrm{O} 3$ tolerant and sensitive trembling aspen (Populus tremuloides Michx.) clones. Forest Genetics, 4, pp 25-33, 1997.

[19] Taylor, Jr. G.E., Role of genotype in the response of loblolly pine to tropospheric ozone: Effects at the whole-tree, stand, and regional level. Journal of Environmental Quality, 23, pp. 63-82, 1994.

[20] Weir, R.J., Genetic variation in loblolly pine (Pinus taeda L.) tolerance to ozone. Ph.D. thesis, North Carolina State Univ. Raleigh, NC., 1977. 